\title{
The Time Course of Phonological Encoding in Language Production: The Encoding of Successive Syllables of a Word
}

\author{
AntJe S. MeYer \\ Max-Planck-Institute for Psycholinguistics, Nijmegen, The Netherlands
}

\begin{abstract}
A series of experiments was carried out investigating the time course of phonological encoding in language production, i.e., the question of whether all parts of the phonological form of a word are created in parallel, or whether they are created in a specific order. A speech production task was used in which the subjects in each test trial had to say one out of three or five response words as quickly as possible. In one condition, information was provided about part of the forms of the words to be uttered, in another condition this was not the case. The production of disyllabic words was speeded by information about their first syllable, but not by information about their second syllable. Experiments using trisyllabic words showed that a facilitatory effect could be obtained from information about the second syllable of the words, provided that the first syllable was also known. These findings suggest that the syllables of a word must be encoded strictly sequentially, according to their order in the word. 1990 Academic Press, Inc.
\end{abstract}

In most theories of language production the meanings and sound forms of content words are represented as separate lexical units (see, for instance, Dell, 1986; Fromkin, 1971; Garrett, 1975, 1980; Kempen \& Hoenkamp, 1987; Levelt, 1989; MacKay, 1982, 1987; Stemberger, 1985). This distinction is supported by evidence from a variety of sources. There are, for instance, the so-called tip-of-the-tongue states, in which the speaker has a feeling of

This paper is based on my Ph.D. dissertation submitted to the University of Nijmegen in 1988. The research was supported by a grant from the MaxPlanck-Gesellschaft zur Förderung der Wissenschaften and carried out at the Max-Planck-Institute for Psycholinguistics, Nijmegen. Preparation of this article was supported in part by a grant of the Deutsche Akademische Austauschdienst and by NIH Grant NS25502-02. I thank J. Weustink for writing the software controlling the experiments; G. Desserjer, $H$. Fransen, and $\mathrm{H}$. Kraayeveld for help in the selection of the stimulus materials and for running four of the experiments; and K. Bock, L. Frazier, A. Lahiri, W. v. Lessen-Kloeke, P. O'Sheaghdha, S. ShattuckHufnagel, A. J. W. M. Thomassen, W. Vonk, and especially W. J. M. Levelt for their helpful comments on drafts of the dissertation manuscript or this article. Reprint requests should be sent to A. S. Meyer, MaxPlanck-Institute for Psycholinguistics, Postbus 310, NL-6500 AH Nijmegen, The Netherlands. knowing a word with a given meaning, but can at most retrieve part of its form (see Browman, 1978; Brown \& McNeill, 1966). Other evidence comes from analyses of speech errors. For example, there are errors in which intended words are replaced by words similar in meaning and cases in which intended words are replaced by words similar in form. Thus, accessing a word apparently involves two steps, the retrieval of its meaning and the retrieval of its form, and errors can arise during both steps (see Fay \& Cutler, 1977; Fromkin, 1971; Garrett, 1975, 1980).

The present research concerns the question of how the form of a word is retrieved given the specification of its meaning. This process will be called phonological encoding. A series of experiments was carried out investigating whether all parts of the form of a word are retrieved at the same time, or whether different parts are retrieved at different times.

Though current models of phonological encoding differ in their details, there are a number of shared assumptions. The phonological representation of a word is usually taken to include a description of the word as a sequence of phonological segments and 
a description of its syllabic structure (see, for instance, Dell, 1986, 1988; ShattuckHufnagel, 1979, 1983; Stemberger, 1985). This view is not only supported by results of speech error analyses (see, for example, Boomer \& Laver, 1968; Fromkin, 1971, 1973; Garrett, 1975, 1980; MacKay, 1970, 1972; Nooteboom, 1969; Shattuck-Hufnagel, 1987; Stemberger, 1983) and other psycholinguistic evidence (see, for instance, Treiman, 1983, 1984, 1986; Treiman \& Danis, 1988), but also by linguistic arguments (e.g., Fudge, 1969; Goldsmith, 1976; Halle \& Vergnaud, 1980; Kahn, 1976; Liberman \& Prince, 1977; Selkirk, 1982, 1984). Syllables are often viewed as frames with slots corresponding to syllable constituents. In addition to, or instead of, syllable frames some models assume word frames, which represent the number and types of syllables words are composed of (see, for instance, Dell, 1988; Shattuck-Hufnagel, 1987; Stemberger, 1984). Phonological encoding is taken to involve three components, namely the retrieval of phonological segments, the creation of syllable and/or word frames, and the association of the segments to the slots of the frames (but see MacKay, 1982, 1987 for a different approach).

The experiments presented below tested certain predictions made by one particular model, namely the spreading activation model proposed by Dell (1986). That model assumes a network of nodes representing linguistic units, such as morphemes, syllables, syllable constituents (consonant clusters and rhymes), segments, and features. Each unit is connected to its constituents. Segments and clusters are marked according to their syllable positions as onset, nucleus, or coda units.

When a polysyllabic morpheme is phonologically encoded, activation spreads in parallel from the morpheme to its syllables and their constituents. At any moment one syllable, the so-called current syllable, is activated more strongly than the remaining syllables. As each node sends a fixed pro- portion of its activation to its neighbors, the constituents of the current syllable also receive more activation than those of the other syllables. The syllables of a morpheme become the current node one after the other, according to their order in the utterance.

While the sublexical units are being activated, a syllable frame is created with three ordered labeled slots corresponding to the syllable onset, nucleus, and coda. After a certain time period, the activation levels of the segments and clusters are inspected, and the most highly activated onset, nucleus, and coda units are selected to fill the slots of the syllable frame. Provided that no error occurs, these units will belong to the current syllable. They are tagged as part of the phonological representation, and their activation is reduced to zero. The activation level of the current syllable is also set to zero, and the next syllable is assigned the current node status. The syllable frame is created again, and after a while it is filled with the segments of the second syllable, and so on, until all syllables of the morpheme have been encoded.

Thus, the selection and ordering of the phonological segments of a morpheme is governed by two mechanisms. As the syllables of a polysyllabic morpheme are assigned current node status in succession, their segments reach their peak activation levels at different points in time and are selected in that order. The segments that are selected when the syllable frame is filled for the first time constitute the first syllable of the word; the segments that are selected when the syllable frame is filled for the second time constitute the second syllable, and so on. By contrast, the segments within a syllable are selected more or less simultaneously and are ordered by association to the ordered slots of the syllable frame.

The assumption that successive syllables of a word are encoded sequentially is shared by a number of models of language production (see, for instance, MacKay, 1982, 1987; Shattuck-Hufnagel, 1979, 1983). 
It is, however, by no means a necessary assumption. For instance, instead of syllable frames, which are created and filled sequentially, there might be frames for entire words, whose slots can be filled in any order. Or it might be the case that word onsets are encoded after the nononset portions of words, as Shattuck-Hufnagel (1987) has suggested.

The experiments reported below tested if the syllables of a word must be encoded in a particular order, or if the order of their encoding is free. Another series of experiments (Meyer, 1988) investigated the time course of phonological encoding inside a syllable. In all of these experiments, a new paradigm, called the implicit priming paradigm, was used, which will be described in the next section.

\section{The Implicit Priming Paradigm}

The implicit priming paradigm made use of a paired-associate learning task. First, the subject learned five pairs of common Dutch nouns, for instance those listed in Table 1. In each of the following test trials, the left-hand member of one of the pairs was presented as a prompt, and the subject named the right-hand member of that pair, the response word, as quickly as possible. The response latency, defined as the interval between prompt onset and speech onset, was the main dependent variable. The

TABLE 1

MATERIALS OF EXPERIMENT 1 (EXAMPLES)

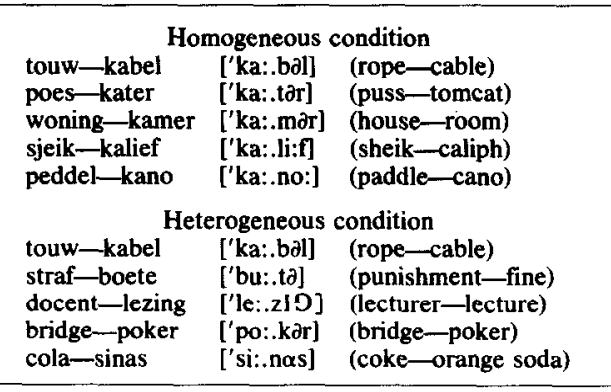

Note. The table lists the word pairs of one homogeneous and one heterogeneous test block, together with a phonetic transcription of the response words and an English translation of the stimuli. items were tested five times each in random order. Then the subject was given performance feedback and went on to study the next group of word pairs, which was tested in the same way. In each block of trials, only those items that had just been studied were tested.

The stimulus materials consisted of a practice set and five experimental sets of five word pairs each. The crucial characteristic of the experimental sets was the systematic phonological relationship among their response words. In Experiment 1, the response words within each set shared the first syllable, as in the above example. In Experiment 2, they shared the second syllable. The string that the response words of a given set had in common will be called the implicit prime.

The experimental word pairs were tested under two conditions. In the homogeneous condition, the five word pairs that were tested together in a block of trials belonged to the same experimental set. Since there were five experimental sets, there were also five different homogeneous test blocks. In each of them, the response words were systematically related in form. In the heterogeneous condition, the same 25 word pairs were used, and each prompt was associated with the same response word as in the homogeneous condition, but the pairs were combined to test blocks in a different way. Again, there were five test blocks, but instead of five word pairs from the same set, each heterogeneous block included one word pair from each of the five sets. Thus, the response words of a heterogeneous test block were not related in form.

Intuition suggests that the creation of the phonological representations of the response words should be easier under the homogeneous than under the heterogeneous condition. There are several ways in which the implicit primes could facilitate the phonological encoding of the response words. First, due to their repeated occurrence, the segments of the first syllable 
could be kept in a heightened state of activation, which might speed their selection and insertion into the syllable frames. According to Dell's model, the activation levels of the first syllable and its segments are set back to zero as soon as the segments have been inserted into the slots of the syllable frame. But since these units still receive some activation from activated feature nodes and from word and conceptual nodes, their activation quickly rebounds from zero and then gradually decays. In the present paradigm the time interval between successive utterances was approximately 2 s. Whether the activation of the segments can survive a time period of that length is an empirical question; but it seems that the facilitatory effect created in this way should be small at most.

A stronger facilitatory effect should arise if the subjects, instead of allowing the activation of the segments to decay between trials, try to keep the recurrent syllable in mind. Dell's model does not include a description of such a process; but a plausible way of thinking of it is to assume that the subjects create a phonological representation of the primed syllable, as they would do if they wanted to utter it overtly, and retain it by periodically recreating it (see Baddeley, Thomson, \& Buchanan, 1975; Conrad, 1964; Dell \& Repka, in press; Ellis, 1980). Thus, keeping a syllable in mind might be a recursive process in which the syllable frame is generated repeatedly, and each time its slots are filled by the same segments. At the end of each cycle, the activation levels of the segments momentarily drop to zero; but the segments are immediatedly reactivated and selected again in the next cycle. In this way, the activation of the recurrent segments remains at a fairly constant level above the resting level. When the phonological encoding of the response word begins, these segments should be selected more rapidly, the phonological encoding should take less time, and the response word should be said sooner than in the heterogeneous control condition.
This expectation is based on the presupposition that the time needed to encode a given syllable depends on how quickly its segments reach a certain level of activation. But in Dell's model a constant time span is devoted to the encoding of each syllable. Activation spreads from the morpheme nodes to the phonological segments, and at fixed time intervals their activation levels are inspected, and the most highly activated onset, nucleus, and coda units that can be found are selected. I do not follow Dell here, but assume that the encoding cycle of a syllable ends as soon as the activation levels of one onset, nucleus, and coda unit have reached a certain threshold (see MacKay, 1982, 1987). The selection threshold is introduced in order to capture the idea that the encoding time per syllable should not be constant, but should depend on how quickly the phonological segments become activated. Moreover, I assume that speakers can select different thresholds, thereby controlling the rate of phonological encoding. The lower the threshold, the faster it is reached by the segments, and the shorter is the duration of the encoding cycles. If these assumptions are correct, the preactivation of the segments of the first syllable should reduce the duration of the first encoding cycle, which should manifest itself in a reduction of the mean reaction time relative to the heterogeneous condition.

A different prediction is made for implicit primes consisting of the second syllable of the response words. When the phonological encoding of a response word begins, activation spreads preferentially to the first syllable and its segments. But the segments of the second syllable receive some activation from the morpheme node, too. If the subjects prepare for the second syllable, in the way discussed above, the activation levels of its segments will initially be higher than those of the segments of the first syllable. If a low selection threshold is chosen, the segments of the second syllable are likely to be selected and to fill the slots of the first syl- 
lable frame because they are still activated above that threshold, while the activation levels of the segments of the first syllable have not yet reached it. To avoid such an error, a fairly high threshold must be selected, which will eventually be reached by the segments of the first syllable, but not by those of the second syllable. Therefore, the encoding of the first syllable will take longer than in the control condition, in which the segments of the second syllable are not activated above the resting level.

While the first syllable is being encoded, the extra activation of the segments of the second syllable decays. Moreover, since a higher selection threshold has been chosen than in the control condition, the second syllable might not be encoded any faster than if it had not been prepared for at all. As the preparation for the second syllable should lead to substantial interference with the encoding of the first syllable and to little or no facilitation of the encoding of the second syllable itself, the mean reaction time should be slower in the homogeneous than in the heterogeneous condition. Alternatively, the subjects might realize that preparation for the second syllable of the response words is not an efficient strategy and might simply ignore the fact that the response words share that syllable. The mean reaction times in the homogeneous and in the heterogeneous conditions should then be identical.

To summarize, if the syllables of a word must be encoded sequentially, implicit primes consisting of different syllables of the response words should differ in their effects. Experiment 1 tested if an implicit priming effect could be obtained from the first syllable of the response words, and Experiment 2 tested if the same was true for the second syllable.

\section{EXPERIMENT 1}

\section{Method}

Subjects. In this experiment, as in all fol- lowing experiments, there were 10 paid subjects, 5 women and 5 men, all undergraduate students at the University of Nijmegen and native speakers of Dutch.

Stimuli. The stimulus materials were constructed in the following way. First, the response words for the five experimental sets were selected. Only common nouns of Dutch were considered, that is, nouns that were expected by three independent raters to be very likely to be known by the subjects. Since the choice of the response words was narrowly constrained by other criteria, it was not possible to use only words with known frequencies. The citation forms were used of all but two words, which appeared in the plural. All response words had two syllables, the first of which was stressed. The vowel of the first syllable was long and was followed by a single consonant. The syllable boundary could be readily determined following the maximal onset principle, which states that of two possible syllabifications of a word that one should be chosen where the syllable onsets include as many segments as possible without creating ill-formed syllables (see Booij, 1981; van der Hulst, 1984). Since Dutch syllables may end in long vowels, the application of this rule assigns only the word-initial consonant and the following vowel to the first syllable, and the word-internal consonant and the following segments to the second syllable. Within each set, the response words shared the first syllable. Otherwise, they were chosen to be as dissimilar in form as possible. There were no obvious semantic relationships among the response words of a set. For the practice set, five phonologically and semantically unrelated response words were selected (see Appendix for a listing of the response words of all experiments).

Next, the response words were combined with prompts. The prompts were selected to be semantically related to the response words they were coupled with and unrelated to the other response words of the set so that the items would be easy to 
learn. Word pairs forming lexicalized compounds were avoided.

Each experimental set represented the stimulus materials for one homogeneous test block. To construct the materials for the heterogeneous test blocks, the items were regrouped. In each heterogeneous test block one word pair from each set was tested. The items were grouped such that the response words within each heterogeneous block were not semantically or phonologically related to each other and that each prompt was semantically related only to the corresponding response word, but not to any other response word of the block.

The word pairs differed from each other in many ways, such as, for example, in the frequency of the two words and in the type of semantic relationship holding between them. But since each word pair was tested both under homogeneous and the heterogeneous condition, all uncontrolled item effects were kept constant across these test conditions.

Apparatus. The experiment was controlled by a Miro GD laboratory computer. Visual information was presented to the subject on an electronic display connected to the computer. Warning tones were played over Sennheiser HD414 headphones. The onset of the subject's response to a prompt was registered by a Sennheiser MD211N microphone and a voice-operated relay interfaced with the computer. The session was taped using a Revox A700 recorder. The experimenter sat in the same room as the subject. The information on the subject's screen, the correct response words, and the subject's reaction times were displayed to the experimenter on a second screen out of sight of the subject.

Design. The design included four crossed within-subject variables. The 25 words pairs formed five sets, in each of which the response words shared the first syllable. The five sets corresponded to the levels of the first variable (sets). Each word pair was tested under the homogeneous condition (i.e., together with the other word pairs of the same set) and under the heterogeneous condition (i.e., together with one word pair from each of the other sets). These two conditions represented the levels of the second variable, whose effect will be called context effect or, synonymously, priming effect. As each word pair was tested five times within a given block, there was a third variable, trials, with five levels. There were 10 test blocks, in which different materials were used, 5 homogeneous ones and 5 heterogeneous ones. Each block was administered three times, and repetitions was the fourth variable.

In addition, the design included one between-subjects variable, groups, with two levels. The group distinction was introduced in order to control for the sequence of homogeneous and heterogeneous test blocks. The experimental session included a block of practice trials and a series of 30 experimental test blocks, which were divided into three parts of 10 test blocks each. Within each part, each homogeneous and each heterogeneous test block were administered once. In the first group of subjects, the first five blocks of each part were homogeneous, and the remaining five blocks were heterogeneous. Conversely, in the second group of subjects, the first five blocks were heterogeneous, and the second five homogeneous.

The five homogeneous and the five heterogeneous blocks were administered in a different random order to each subject in each of the three parts of the experiment. The order of the word pairs within a block was also random, except that repetitions of word pairs in successive trials were avoided. Different random sequences were generated for all test blocks and subjects.

Procedure. The subjects were tested individually. After the subject had read the instruction, the practice block was administered, followed by the 30 experimental blocks. The experiment consisted of alternating presentation and test phases. In a presentation phase, the subject was given 
an index card on which the word pairs for the following block were printed and was asked to memorize them until he or she was certain that he or she knew which response word each prompt was combined with. Usually, it took the subject no longer than about 2 min to learn the five word pairs of a block. By the 5th test block, the subject had studied all items. Still, thoughout the entire experiment, a list of the relevant word pairs was presented prior to each block of test trials so that the subject was always informed about the upcoming items.

As soon as the subject indicated that he or she had sufficiently studied the word pairs, the experimenter started the test phase. At the beginning of each trial the subject heard a high warning tone $(1000 \mathrm{~Hz})$ and simultaneously saw two horizontal fixation bars marking the left and right margins of the field where the prompt would be displayed shortly afterwards. The bars appeared in the same locations on all trials, regardless of the length of the prompt. The tone and the fixation bars were displayed for $200 \mathrm{~ms}$ and were followed by a $600-\mathrm{ms}$ pause. Then the prompt was presented for $150 \mathrm{~ms}$, and the subject said the response word as fast as possible. The speech onset was detected by the voice key, and the reaction time, measured from prompt onset, was computed and written into a data file. The prompt display was followed by a blank interval of $1050 \mathrm{~ms}$. Then the next trial began. If the subject failed to react within $1000 \mathrm{~ms}$ after prompt onset, a low tone $(500 \mathrm{~Hz})$ was played for $200 \mathrm{~ms}$, and $200 \mathrm{~ms}$ later the next trial began. The subjects were instructed to avoid this tone by reacting quickly enough.

The experimenter monitored the responses and marked errors in the data file. A response was considered incorrect if the subject failed to respond, used a wrong response word, stuttered, began with a filled pause, or repaired the utterance. The mean reaction time, the number of errors, and the number of slow responses (that is, responses with latencies longer than $1000 \mathrm{~ms}$ ) were transformed into scores, which were displayed to the subject at the end of each block of test trials. The subject earned one point for each correct response and lost two points for each incorrect response and one point for each slow response and for each 100-ms mean reaction time. In order to keep track of his or her performance, the subject entered the total number of points earned in each block into a form.

Data analyses. On the basis of the taped performance record, invalid data points were identified and excluded from further analyses. In addition to incorrect and slow responses, two other classes of data points were eliminated from the analyses, namely responses that began with mouth clicks (that is, with clicking or smacking nonspeech sounds produced by the lips or the tongue) and data points stemming from trials on which the equipment did not function properly or the voice key was triggered by noise in the environment. ${ }^{1}$

The valid reaction times from the five items of each set were combined to means per subject, context, repetition, and trial. The resulting scores were submitted to an analysis of variance with the betweensubjects variable groups and the withinsubject variable sets, contexts, trials, and repetitions. Geisser-Greenhouse conservative $F$ tests were used. The generality of the findings across different materials was assessed by replicating important experimental conditions in several experiments with different word pairs.

Occasionally, the durations of the subjects' utterances were measured. In those cases, the responses were digitized using a $10-\mathrm{kHz}$ sampling rate and a $5-\mathrm{kHz}$ low pass filter setting. Measurements were made using a waveform editing system. The utterance durations were analyzed in the same way as the reaction times, i.e., the mea-

\footnotetext{
1 The error percentages given in the tables do not include missing values of the last mentioned type. Their percentages in Experiments 1 through 6 were, in order, $2.25,2.53,0.60,0.79,0.45$, and $0.26 \%$.
} 
TABLE 2

Results of Experiment 1: Mean Reaction Times, Priming Effects, and Error Rates per Set

\begin{tabular}{ccccccc}
\hline & \multicolumn{5}{c}{ Statistic } \\
\cline { 2 - 6 } & RT(hom) & RT(het) & Diff & $F(1,8)$ & $e \%$ (hom) & $e \%$ (het) \\
\hline Set prime & & & & & \\
I ['bu:] . . & 630 & 645 & 15 & 1.63 & 14.27 & 8.67 \\
2 ['ka:] . . & 548 & 637 & 89 & $59.86^{* *}$ & 3.47 & 5.33 \\
3 ['le:] . . & 542 & 609 & 67 & $34.87^{* *}$ & 4.13 & 4.27 \\
4 ['po:] ... & 606 & 666 & 60 & $27.58^{* *}$ & 6.80 & 6.67 \\
5 ['si:] . . & 573 & 615 & 42 & $13.90^{* *}$ & 4.27 & 4.80 \\
Mean & 580 & 635 & 55 & & 6.59 & 5.95 \\
\hline
\end{tabular}

Note. The table displays, for each set, the mean reaction times in the homogeneous and heterogeneous conditions (RT(hom) and RT(het)), the difference between the conditions (Diff, defined as RT(het)-RT(hom)), the $F$ value from the analysis of simple effects, and the error percentages in the homogeneous and heterogeneous conditions $\left(e \%(\right.$ hom) and $e \%($ het $)) . M S_{\mathrm{e}}$ is the error term used in the analysis of simple effects. $M S_{\mathrm{e}}=9749$.

$* * p<.01$.

sured values were combined to means per subject, set, context, repetition, and trial and were submitted to an analysis of variance.

\section{Results and Discussion}

In Experiment 1, the mean reaction time was shorter by $55 \mathrm{~ms}$ in the homogeneous than in the heterogeneous condition, and the corresponding context effect was highly significant (means: 580 and $635 \mathrm{~ms}, F(1,8)$ $\left.=34.94, M S_{\mathrm{e}}=31,869, p<.01\right)$. Thus, as predicted, the subjects could produce the response words of a block more rapidly when they shared the first syllable than when this was not the case. Table 2 shows that this held for all sets; but the priming effect was more pronounced in some sets than in others, which is reflected in the significant interaction of sets and contexts $\left(F(1,8)=13.65, M S_{\mathrm{e}}=4219, p<.01\right)$. An analysis of simple effects showed that the priming effect was significant in four of the five sets.

The main effect of sets was also significant (means for Sets 1 to 5: 637, 592, 576, 636 , and $594 \mathrm{~ms}, F(1,8)=23.62, M S_{\mathrm{e}}=$ $10,001, p<.01$ ), which indicates that the response words of some sets could be retrieved faster than those of others, regardless of whether they were tested together with the other words of the same set or with words from other sets. As one might expect, the mean reaction times decreased over the three repetitions of the test blocks (means for Repetitions 1, 2, and 3: 633, 597, and $591 \mathrm{~ms}, F(1,8)=15.05, M S_{\mathrm{e}}=17103$, $p<.01) .^{2}$ Finally, the interaction of groups, contexts, and repetitions was also significant $\left(F(1,8)=9.74, M S_{e}=6974, p<.05\right.$; see Table 3). The mean reaction time was shorter in the homogeneous than in the heterogeneous condition in all repetitions of both groups of subjects. But in the first repetition, the priming effect was weak (11 ms) and not significant in the first group, whereas it was particularly pronounced $(82$ ms) and highly significant in the second group. The two groups differed in the order of the homogeneous and the heterogeneous conditions. In Group 1 the homogeneous test blocks preceded the heterogeneous

\footnotetext{
${ }^{2}$ The main effect of sets was also significant in three other experiments, namely in Experiments 2, 4, and 6. The main effect of repetitions was significant in all experiments; and in Experiments 3 and 4, the main effect of trials was likewise significant. In Experiment 6 , a significant main effect of the variable groups was obtained. Since these effects are of no theoretical interest in the current context, the corresponding statistics are not reported, but can be provided by the au-
} thor. 
TABLE 3

Results of Experiment 1: Mean reaction Times and Priming Effects per Group and Repetition

\begin{tabular}{|c|c|c|c|c|}
\hline \multirow[b]{2}{*}{ Condition } & \multicolumn{4}{|c|}{ Statistic } \\
\hline & RT(hom) & RT(het) & Diff & $F(1,8)$ \\
\hline \multicolumn{5}{|l|}{ Group 1} \\
\hline Repetition 1 & 629 & 640 & 11 & 0.50 \\
\hline Repetition 2 & 571 & 626 & 55 & $12.38^{* *}$ \\
\hline Repetition 3 & 564 & 634 & 70 & $20.05^{* *}$ \\
\hline Mean & 588 & 633 & 45 & \\
\hline \multicolumn{5}{|l|}{ Group 2} \\
\hline Repetition 1 & 591 & 673 & 82 & $28.19^{* *}$ \\
\hline Repetition 2 & 571 & 620 & 49 & $9.83^{*}$ \\
\hline Repetition 3 & 555 & 613 & 58 & $13.30^{* *}$ \\
\hline Mean & 572 & 635 & 63 & \\
\hline
\end{tabular}

Note. The table displays, for each group and repetition, the mean reaction times in the homogeneous and heterogeneous conditions (RT(hom) and RT(het)), the difference between the conditions (Diff, defined as RT(het)-RT(hom)), and the $F$ value from the analysis of simple effects. $M S_{e}$ is the error term used in the analysis of simple effects. $M S_{\mathrm{e}}=15272$.

${ }^{*} p<.05$.

${ }^{* *} p<.01$.

ones within each of the three parts of the experiment, whereas the reverse was true in Group 2. Most likely the repetition of the word pairs speeded the reactions because, for instance, the associations between the prompts and the response words became more firmly established, and the response words could be selected more rapidly. This practice effect added to the effect of the test contexts in Group 2 and partially canceled it in Group 1. Apparently the order of administering the homogeneous and heterogeneous conditions noticeably affected the reaction times only in the first repetition.

\section{EXPERIMENT 2}

\section{Stimuli}

Five experimental sets of five word pairs each were created in which the response words shared the second syllable (see Table 4 for an example). Most words (as, for instance, "foto") included a single wordinternal consonant, which, according to the maximal onset principle, formed the onset of the second syllable. Other words (such as, for instance, "salto") included word- internal consonant sequences that did not constitute possible onset clusters of Dutch. In those cases, the onset of the second syllable only included the second consonant of the sequence, whereas the first consonant was part of the preceding syllable rhyme. As in Experiment 1, the word pairs were tested under a homogeneous and a heterogeneous test condition. Under the homogeneous condition, one complete set was tested in each block. Under the heterogeneous condition, each block included one word pair from each set.

\section{Results and Discussion}

In Experiment 2, the mean reaction times in the homogeneous and in the heteroge-

TABLE 4

MATERIALS OF EXPERIMENT 2 (EXAMPLES)

$\begin{array}{lll}\text { circus-salto } & \text { ['sal.to:] } & \text { (circus-somersault) } \\ \text { besluit-veto } & \text { ['ve:.to:] } & \text { (decision-veto) } \\ \text { camera-foto } & \text { ['fo:.to:] } & \text { (camera-photograph) } \\ \text { bedrag-conto } & \text { ['kon.to:] } & \text { (amount-account) } \\ \text { wagen-auto } & \text { ['ou.to:] } & \text { (waggon-car) }\end{array}$

Note. The table lists the word pairs of one set, together with a phonetic transcription of the response words and an English translation of the stimuli. 
TABLE 5

Results of Experiment 2: Mean Reaction Times, Priming Effects, and Error Rates per Set

\begin{tabular}{lcccrr}
\hline & \multicolumn{5}{c}{ Statistic } \\
\cline { 2 - 6 } & RT(hom) & RT(het) & Diff & $e \%$ (hom) & $e \%$ (het) \\
\hline Set prime & & & & & \\
$1 \ldots$ [dID] & 624 & 629 & 5 & 9.07 & 6.93 \\
$2 \ldots$ [ma:] & 651 & 639 & -12 & 9.73 & 11.07 \\
$3 \ldots$ [ri:] & 622 & 625 & 3 & 11.73 & 6.93 \\
$4 \ldots$ [to:] & 639 & 632 & -7 & 10.93 & 9.73 \\
$5 \ldots$ [zdl] & 638 & 634 & -4 & 11.20 & 12.67 \\
Mean & 635 & 632 & -3 & 10.53 & 9.47 \\
\hline
\end{tabular}

neous condition were virtually identical (means: 635 and $632 \mathrm{~ms}, F(1,8)=0.80$, $M S_{\mathrm{e}}=420$; see Table 5). In other words, no priming effect was observed.

In discussing the results of Experiment 1, it was argued that in addition to the effect of the implicit primes there was a practice effect, which speeded the reactions in those blocks that were tested last within each of the three parts of the experiment. In the present experiment, only a practice effect was observed. In both groups of subjects, the mean reaction time was shorter in those blocks that were tested in the second half of each part of the experiment. These were the heterogeneous blocks in the first group of subjects and the homogeneous blocks in the second group. This interaction of groups and contexts was statistically significant $\left(F(1,8)=12.26, M S_{\mathrm{e}}=4207, p<\right.$
.01). As in the first experiment, the order of testing the two types of blocks strongly affected the reaction times in the first repetition and then lost its impact, which is the reason why the interaction of groups, contexts, and repetitions was also significant $\left(F(1,8)=11.71, M S_{\mathrm{e}}=2770, p<.01 ;\right.$ see Table 6).

Thus, the implicit primes of Experiment 2 did not affect the response latencies in any systematic way. A test to determine if they affected the time necessary to complete the utterances was also performed. The duration of the responses, defined as the time interval between the onset of the word-initial segment and the offset of the word-final segment, was measured for all correct responses in the second repetition of the experiment. The mean duration of the responses was slightly longer in the ho-

TABLE 6

Results of Experiment 2: Mean Reaction Times and Priming Effects per Group and Repetition

\begin{tabular}{|c|c|c|c|c|}
\hline \multirow[b]{2}{*}{ Condition } & \multicolumn{4}{|c|}{ Statistic } \\
\hline & RT(hom) & RT(het) & Diff & $F(1,8)$ \\
\hline \multicolumn{5}{|l|}{ Group 1} \\
\hline Repetition 1 & 670 & 636 & -34 & $23.57^{* *}$ \\
\hline Repetition 2 & 624 & 608 & -16 & 4.93 \\
\hline Repetition 3 & 608 & 614 & 6 & 0.95 \\
\hline Mean & 634 & 620 & -14 & \\
\hline \multicolumn{5}{|l|}{ Group 2} \\
\hline Repetition 1 & 657 & 680 & 23 & $10.18^{*}$ \\
\hline Repetition 2 & 625 & 630 & 5 & 0.48 \\
\hline Repetition 3 & 623 & 623 & 0 & 0.17 \\
\hline Mean & 635 & 644 & 9 & \\
\hline
\end{tabular}

\footnotetext{
$M S_{\mathrm{e}}=3249$

${ }^{*} p<.05$.

$* * p<.01$.
} 
mogeneous than in the heterogeneous condition, but this difference was not significant (means: 445 vs. $436 \mathrm{~ms}, F(1,8)=2.07$, $\left.M S_{\mathrm{e}}=4490\right)$. None of the interactions involving the context effect were significant, either.

Experiments 1 and 2 showed that implicit primes consisting of the first syllable of the response words speeded the responses, whereas implicit primes consisting of the second syllable had no effect. But the response words used so far were all stressed on the first syllable. Therefore, the results are open to two interpretations, namely that the priming effect depended on the word position of the primed syllable, or that it depended on its stress value. In order to decide between these accounts, the next two experiments were run, using disyllabic response words that were stressed on the second syllable. In Experiment 3 they were primed by their first syllable; and in Experiment 4 , by their second syllable. If the priming effect hinges on the word position of the primed syllable, it should appear in Experiment 3, but not in Experiment 4. Conversely, if the effect depends on the stress value of the primed syllable, it should be found in Experiment 4, but not in Experiment 3 .

\section{EXPERIMENT 3}

\section{Stimuli}

The response words of Experiment 3 were disyllabic nouns in which the main stress fell on the second syllable. The first syllable, which was the implicit prime, consisted of a consonant and a long vowel (see Table 7). ${ }^{3}$

\footnotetext{
${ }^{3}$ Inadvertently, one response word was included in the materials whose first vowel was short ("rapport"). Since Dutch syllables may not end in short full vowels, the word-internal consonant in words of this structure is usually taken to be ambisyllabic; i.e., to be part of both syllables (see Booij, 1981). Thus, the first syllable of "rapport" is different from the first syllable of the remaining response words of the set. The reaction times stemming from "rapport" were not included in the data analyses.
}

TABLE 7

Materials of EXPERIMENT 3 (EXAMPLes)

$\begin{array}{lll}\text { ster-komeet } & \text { [ko:.'me:t] } & \text { (star-comet) } \\ \text { haas-konijn } & \text { [ko:.'nein] } & \text { (hare-rabbit) } \\ \text { soldaat-kozak } & \text { [ko:.'zak] } & \text { (soldier-cossack) } \\ \text { rif-koraal } & \text { [ko:.'ra:l] } & \text { (reef-coral) } \\ \text { namaak-kopie } & \text { [ko:.'pi:] } & \text { (imitation-copy) }\end{array}$

\section{Results}

In Experiment 3, the mean reaction time was shorter by $43 \mathrm{~ms}$ in the homogeneous than in the heterogeneous condition (means: 631 and $674 \mathrm{~ms}, F(1,8)=51.81$, $\left.M S_{\mathrm{e}}=13,342, p<.01\right)$. Thus, the response words were implicitly primed by their first syllable, even when that syllable was unstressed. There was some variation in the strength of the effect across the sets, but the interaction of contexts and sets was not significant $\left(F(1,8)=1.96, M S_{\mathrm{e}}=3396\right.$; see Table 8). The only significant interaction was the interaction of groups and contexts $\left(F(1,8)=6.16, M S_{\mathrm{e}}=13,342, p<.05\right)$. The difference between the homogeneous and the heterogeneous condition was significant in both groups of subjects, but it was less pronounced in the second than in the first group (means for Group 1: 645 and 673 $\mathrm{ms}, F(1,8)=11.12, p<.05$; means for Group 2: 617 and $675 \mathrm{~ms}, F(1,8)=46.84, p$ $<.01)$.

\section{EXPERIMENT 4}

\section{Stimuli}

In Experiment 4, the response words were implicitly primed by their stressed second syllable (see Table 9). The first syllable of the response words consisted of a single consonant or a consonant cluster, followed by a long vowel or by a short vowel and a consonant. The second syllable included an onset consonant, a vowel, and a coda consonant.

\section{Results and Discussion}

No priming effect was observed in Experiment 4 . The mean reaction time was longer by $7 \mathrm{~ms}$ in the homogeneous than in the heterogeneous condition (means: 678 
TABLE 8

Results of Experiment 3: Mean Reaction Times, Priming Effects, and Error Rates per Set

\begin{tabular}{|c|c|c|c|c|c|}
\hline & \multicolumn{5}{|c|}{ Statistic } \\
\hline & RT(hom) & RT(het) & Diff & $e \%$ (hom) & $e \%$ (het) \\
\hline \multicolumn{6}{|l|}{ Set prime } \\
\hline 1 [bu:]. & 623 & 662 & 39 & 6.53 & 5.47 \\
\hline 2 [de:] . . & 659 & 688 & 29 & 7.73 & 4.80 \\
\hline 3 [ko:] . . . & 617 & 670 & 53 & 9.07 & 5.47 \\
\hline $4[\mathrm{ra}:] \ldots$ & 637 & 682 & 45 & 2.93 & 5.47 \\
\hline 5 [si:] . . & 619 & 668 & 49 & 6.93 & 5.87 \\
\hline Mean & 631 & 674 & 43 & 6.64 & 5.41 \\
\hline
\end{tabular}

and $671 \mathrm{~ms}, F(1,8)=1.65, M S_{\mathrm{e}}=12,469$; see Table 10). As in Experiment 2, the interaction of groups and contexts and the interaction of groups, contexts, and repetitions were significant $\left(F(1,8)=17.17, M S_{\mathrm{e}}\right.$ $=12,469, p<.01$ and $F(1,8)=35.63, M S_{\mathrm{e}}$ $=3219, p<.01$, respectively). The pattern of results could again be explained by reference to a practice effect that favored the heterogeneous test blocks in the first group of subjects and the homogeneous test blocks in the second group and that was stronger at the beginning than at the end of the experiment.

Taken together Experiments 1 to 4 showed that the effects of the implicit primes depended on the word position of the primed syllables rather than on their stress value. When the response words shared the first syllable, the subjects apparently used the primes to prepare for the utterance. When the response words shared the second syllable, one of two things could have happened. First, the subjects might have prepared for the words by creating and retaining a representation of the primed syllable. This facilitated the phonological encoding of the second syllable, but it interfered with the encoding of the first syl-

TABLE 9

Materials of EXPERIMENT 4 (EXAMPLES)

grootte-formaat [for.'ma:t] (size-format) chemie_bromaat [bro:.'ma:t] (chemistry-bromate) sla-tomaat weer-klimaat [to:.'ma:t] (lettuce-tomato) [kli:.'ma:t] (weather-climate) gorilla-primaat [pri:.'ma:t] (gorilla-primate) lable of the response words, and these two effects canceled each other. Or, second, the subjects might have realized that preparing for the second syllable was not an efficient strategy and simply ignored the fact that the response words shared that syllable.

Of these two accounts, the second is not only more parsimonious, but also more plausible. The mean reaction times in the homogeneous and heterogeneous conditions differed by only $3 \mathrm{~ms}$ in Experiment 2 and by $7 \mathrm{~ms}$ in Experiment 4 . If two processes were induced by the implicit primes, they must have been exactly equally strong, which, though possible, does not seem very likely. Also, if the subjects prepared for the second syllable of the response words, one might expect errors in which the first syllable frame was filled by the segments of the second syllable. But neither complete reversals of the two syllables of a response word nor anticipations of the second syllable were ever observed.

Irrespective of which of the two accounts is correct, the data show that efficient preparation for the utterances was only possible on the basis of the first syllable of the response words. This can be explained on the assumption that successive syllables of a word must be phonologically encoded one after the other, according to their order in the word, and that this order must be retained in preparing for a word on the basis of an implicit prime. This explanation leads to the prediction that speakers should be able to prepare themselves for a given word 
TABLE 10

Results of Experiment 4: Mean Reaction Times, Priming Effects, and Error Rates per Set

\begin{tabular}{lccccc}
\hline & \multicolumn{5}{c}{ Statistic } \\
\cline { 2 - 6 } & RT(hom) & RT(het) & Diff & e\%(hom) & e\%(het) \\
\hline Set prime & & & & & \\
$1 \ldots$ ['ket] & 683 & 673 & -10 & 5.47 & 5.20 \\
$2 \ldots$ ['ma:t] & 687 & 682 & -5 & 7.73 & 5.73 \\
$3 \ldots$ ['nlk] & 681 & 679 & -2 & 6.13 & 3.87 \\
$4 \ldots$ ['ses] & 694 & 678 & -16 & 11.47 & 5.33 \\
$5 \ldots$ ['ty:r] & 646 & 641 & -5 & 5.20 & 4.13 \\
Mean & 678 & 671 & -7 & 7.20 & 4.85 \\
\hline
\end{tabular}

on the basis of information about its second syllable, provided that the first syllable is also known. Experiment 5 tested this prediction. Trisyllabic response words were used, which were either implicitly primed by their first syllable alone or by their first and second syllable together. A stronger priming effect was expected from the disyllabic than from the monosyllabic primes.

\section{EXPERIMENT 5}

\section{Stimuli and Design}

Six experimental sets with three word pairs each were generated. With one exception, the response words had three syllables, the last of which was stressed; one response word had four syllables and was stressed prefinally. In three sets, called type 1 sets hereafter, the response words shared the first syllable. In the remaining sets, called type 2 sets, they shared the first and second syllable (see Table 11 for examples). The set size was reduced to three word pairs because it was impossible to find larger groups of monomorphemic nouns with at least three syllables that shared the first two syllables and had the same stress pattern. In order to create test blocks of about the same length as in Experiments 1 to 4 , the number of trials per word pair and test block was increased from five to eight.

\section{Results}

The main effect of contexts was significant (means: 591 and $614 \mathrm{~ms}, F(1,8)=$ 12.28, $M S_{\mathrm{e}}=32,322, p<.01$; see Table $12)$. In the type 1 sets the mean priming effect was $14 \mathrm{~ms}$, and in the type 2 sets it was $32 \mathrm{~ms}$. In planned comparisons both effects were significant (means for the type 1 sets: 599 and $613 \mathrm{~ms}, t(8)=2.34, p<.05$; means for the type 2 sets: 583 and $615 \mathrm{~ms}$, $t(8)=5.42, p<.01) .{ }^{4}$ The 18 -ms difference in the strength of the effect between the two set types was also significant $(t(8)=2.12, p$ $<.05$ ).

\footnotetext{
${ }^{4}$ One-tailed $t$ tests were used in planned comparisons.
}

\section{TABLE 11}

MATERIALS OF EXPERIMENT 5 (EXAMPLES)

\begin{tabular}{llll}
\hline & \multicolumn{2}{c}{ Type 1 set } \\
fruit-mirabel & [mi:.ra:.'bel] & (fruit-mirabelle) \\
omroep-microfoon & [mi:.kro:.'fo:n] & (broadcasting-microphone) \\
gesteente-mineraal & [mi:.nd.'ra:l] & (stone-mineral) \\
& \multicolumn{2}{c}{ Type 2 set } \\
hel-paradijs & [pa:.ra:.'deis] & (hell-paradise) \\
worm-parasiet & [pa:.ra:.'si:t] & (worm-parasite) \\
regen-paraplu & [pa:.ra:.'ply:] & (rain-umbrella) \\
\hline
\end{tabular}


TABLE 12

Results of Experiment 5: Mean Reaction Times, Priming Effects, and Error Rates Per Set

\begin{tabular}{|c|c|c|c|c|c|c|}
\hline & \multicolumn{6}{|c|}{ Statistic } \\
\hline & RT(hom) & RT(het) & Diff & $F(1,8)$ & $e \%$ (hom) & $e \%$ (het) \\
\hline \multicolumn{7}{|c|}{ Type 1 sets } \\
\hline \multicolumn{7}{|l|}{ Set prime } \\
\hline $1[\alpha r] \ldots$ & 613 & 606 & -7 & 0.50 & 15.97 & 8.33 \\
\hline $2[\mathrm{mi}:] \ldots$ & 582 & 613 & 31 & $8.86^{*}$ & 9.58 & 9.72 \\
\hline $3[$ pe:] ... & 601 & 621 & 20 & 3.67 & 7.08 & 6.94 \\
\hline Mean & 599 & 613 & 14 & & 10.88 & 8.33 \\
\hline \multicolumn{7}{|c|}{ Type 2 sets } \\
\hline \multicolumn{7}{|l|}{ Set prime } \\
\hline $4[\operatorname{In} t \partial] \ldots$ & 605 & 599 & -6 & 0.50 & 11.53 & 7.92 \\
\hline 5 [ko:lo:] ... & 567 & 631 & 64 & $38.07^{* *}$ & 11.81 & 10.28 \\
\hline 6 [pa:ra:] . . & 576 & 616 & 40 & $14.16^{* *}$ & 8.06 & 7.08 \\
\hline Mean & 583 & 615 & 32 & & 10.47 & 8.43 \\
\hline
\end{tabular}

Thus, as predicted, the priming effect was stronger when the response words shared the first and second syllable than when they shared only the first syllable. But, compared to Experiments 1 and 3, where priming effects of 55 and $43 \mathrm{~ms}$ had been observed, the priming effects in the present experiment-14 ms for monosyllabic primes and $32 \mathrm{~ms}$ for disyllabic oneswere relatively weak. The Sets $\times$ Contexts interaction was significant $(F(1,8)=9.94$, $M S_{\mathrm{e}}=9067, p<.05$ ), and, as can be seen from Table 12, the priming effect was significant in only three of the six sets. Smaller sets and longer response words were used than before, and the frequency of the response words in spoken and written language was probably lower. These factors might, in some unknown way, have de- pressed the priming effects. Because of the weakness of the effects, the experiment was repeated with new stimulus materials.

\section{EXPERIMENT 6}

\section{Stimuli}

There were again six sets with three word pairs each, three type 1 sets, in which the response words shared the first syllable (type 1 sets), and three type 2 sets, in which they shared the first and second syllable (type 2 set, see Table 13). As it was impossible to find enough appropriate monomorphemic response words for Experiment 6, two sets were included in which the primed syllables were prefixes ("epi" and "mono"). The results were analyzed separately for these and the other sets. Except

TABLE 13

MATERIALS OF EXPERIMENT 6 (EXAMPLES)

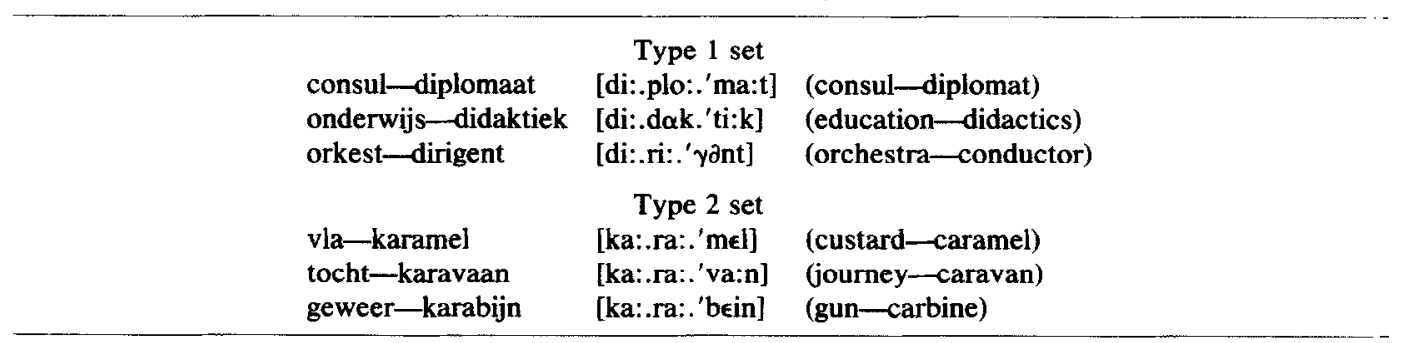


for two words with four syllables and prefinal stress, all response words had three syllables, the last of which was stressed.

\section{Results}

In Experiment 6 substantially stronger priming effects were obtained than in Experiment 5 . The mean reaction time was shorter by $55 \mathrm{~ms}$ in the homogeneous than in the heterogeneous condition (means: 563 and $618 \mathrm{~ms}, F(1,8)=30.20, M S_{\mathrm{e}}=71,536$, $p<.01)$. The interaction of sets and contexts was significant $\left(F(1,8)=11.81, M S_{\mathrm{e}}\right.$ $=12,067, p<.01$; see Table 14). In all sets, the mean reaction time was shorter in the homogeneous than in the heterogeneous condition, but the difference failed to reach significance in two sets. The priming effects were 26 and $83 \mathrm{~ms}$ for the type 1 and type 2 sets, respectively. Both effects were significant (means for the type 1 sets: 590 and 616 $\mathrm{ms}, t(8)=3.45, p<.01$; means for the type 2 sets: 536 and $619 \mathrm{~ms}, t(8)=10.62, p<$ $.01)$. The 57 -ms difference between the two effects was also significant $(t(8)=5.07, p<$ .01 ).

The priming effects were particularly strong in those two type 2 sets in which the implicit primes were prefixes. However, the difference in the strength of the mean priming effect for these sets and for the third type 2 set, in which the implicit prime ("kara") was not a prefix, was not significant (priming effects: 91 and $67 \mathrm{~ms}, t(8)=$ 1.35). The effect in the "kara"-set was significantly stronger than the mean effect in the three type 1 sets $(t(8)=2.62, p<.05)$. Thus, the disyllabic primes were more efficient than the monosyllabic ones, regardless of whether they were prefixes or not.

As in Experiments 2, 3, and 4, the interaction of groups and contexts was significant $\left(F(1,8)=12.63, M S_{\mathrm{e}}=71,536, p<\right.$ $.01)$. In both groups of subjects, the mean reaction time was shorter in the homogeneous than in the heterogeneous condition, but this difference was only significant in Group 2 (means for Group 1: 620 and 640 $\mathrm{ms}, F(1,8)=1.89$; means for Group 2: 505 and $596 \mathrm{~ms}, F(1,8)=40.95, p<.01)$. As was discussed above, this interaction is most likely due to a practice effect favoring the heterogeneous test blocks in the first group of subjects and the homogeneous ones in the second group.

\section{General Discussion}

The results of the six experiments reported above can be summarized in the following way: In experiments using disyllabic

TABLE 14

Results uf Experiment 6: Mean Reaction Times, Priming Effects, and Error Rates per Set

\begin{tabular}{|c|c|c|c|c|c|c|}
\hline & \multicolumn{6}{|c|}{ Statistic } \\
\hline & RT(hom) & RT(het) & Diff & $F(1,8)$ & $e \%$ (hom) & $e \%$ (het) \\
\hline \multicolumn{7}{|c|}{ Type 1 sets } \\
\hline \multicolumn{7}{|l|}{ Set prime } \\
\hline 1 [ba:] ... & 598 & 614 & 16 & 1.40 & 6.25 & 4.72 \\
\hline 2 [di:] . . & 603 & 623 & 20 & 2.13 & 7.78 & 7.08 \\
\hline 3 [e:] . . & 567 & 611 & 44 & $10.50^{*}$ & 9.72 & 6.25 \\
\hline Mean & 590 & 616 & 26 & & 7.92 & 6.02 \\
\hline \multicolumn{7}{|c|}{ Type 2 sets } \\
\hline \multicolumn{7}{|l|}{ Set prime } \\
\hline 4 [e:pi:] . . . & 532 & 611 & 79 & $33.89^{* *}$ & 9.31 & 5.97 \\
\hline 5 [ka:ra:] . . & 556 & 623 & 67 & $24.37^{* *}$ & 7.78 & 4.86 \\
\hline 6 [mo:no:] . . & 521 & 624 & 103 & $58.43^{* *}$ & 6.25 & 5.00 \\
\hline Mean & 536 & 619 & 83 & & 7.78 & 5.28 \\
\hline
\end{tabular}

$M S_{\mathrm{e}}=21,978$.

${ }^{*} p<.05$.

$* * p<.01$. 
response words, implicit priming effects were observed when the response words shared the first syllable, but not when they shared the second syllable. In experiments using trisyllabic response words, stronger priming effects were observed when the primes included the first and the second syllable of the response words than when they included only the first syllable.

These results were predicted on the basis of the model of phonological encoding described in the Introduction. When the first syllable of the response words was implicitly primed, the subjects presumably generated and retained a phonological representation of that syllable. This can be viewed as a cyclic process, in which the syllable frame is created a number of times and is filled each time by the segments of the first syllable. Due to this process the activation of the recurrent segments is raised to a fairly stable level above the resting level. When the phonological encoding of the response word begins, these segments reach the selection threshold more rapidly, and the utterance latency is shorter than in the heterogeneous control condition.

According to the proposed model, the segments of the second syllable of a word must not be more highly activated than those of the first syllable when the phonological encoding begins; otherwise, the two sets of segments compete with each other for insertion into the first syllable frame. When only the second syllable of the response words was primed, the subjects probably realized that preparing for it was not an cfficient strategy and simply ignored the fact that it was shared by all response words of the block. Hence, no priming effect was observed.

Finally, when the first and second syllable were primed, the subjects presumably created and retained a phonological representation of both syllables. This can be viewed as a process in which the segments of the first and of the second syllable are alternately inserted into the slots of the syllable frame so that the activation level of both sets of segments is raised above the resting level. Consequently, the phonological encoding of both syllables was facilitated, and the priming effect was stronger than when only the first syllable is primed.

Thus, the results can be explained within the proposed model of phonological encoding. But this interpretation presupposes that the implicit primes actually affected the phonological encoding of the response words, rather than other processes involved in the planning of the utterances. In the following, some alternative accounts of the priming effects will be discussed.

A first possibility is that when the primes consisted of the first one or two syllables of the response words, the subjects first said those syllables and then selected the response words and added the missing syllables. In that case, the response words would be produced in a way that has little in common with the way words are normally produced. But if the subjects had adopted this strategy, the reactions should have been much faster than they actually were. Using the equipment of the current study, Kraayeveld (1988) ran an experiment in which a single mono- or trisyllabic word was tested in each block. In this experiment, the subjects could generate the complete phonological form of the response word in advance and only had to utter it as soon as the prompt appeared on the screen. If the subjects in the present experiments said the primed syllables immediately upon the presentation of the prompts and then selected the response words, the mean reaction times should have been about the same as in Kraayeveld's experiments. They were, however, longer by approximately $200 \mathrm{~ms}$. This suggests that the subjects in the implicit priming experiments engaged in certain planning processes before initiating the utterance that were not necessary in Kraayeveld's experiment. Most likely, they read the prompt, selected a response word, and generated its phonological representation.

Also, if the subjects performed some of 
the planning that is normally done prior to the utterance onset while they were already articulating the first syllable of the response word, one might expect them to lengthen that syllable slightly in order to gain extra time for these processes. This expectation was tested for Experiment 1, in which the implicit primes consisted of the first syllable of the response words, and for Experiment 6 , in which they consisted either of the first syllable (type 1 sets) or of the first and second syllable of the response words (type 2 sets), by measuring and comparing the durations of these syllables in the homogeneous and in the heterogeneous condition. ${ }^{5}$ In Experiment 1, the mean durations of the first syllable of the response words in the homogeneous and the heterogeneous conditions were 194 and $191 \mathrm{~ms}$, respectively. The corresponding means for the type 1 sets of Experiment 6 were 94 and $92 \mathrm{~ms}$, and for the type 2 sets they were 188 and $195 \mathrm{~ms}$, respectively. None of these differences was statistically significant. Hence, it seems unlikely that the subjects first uttered the primed syllables and then selected the response words.

Another possible account of the priming effects is that they were due to motor preparation. When the response words shared the first syllable, the subjects could bring their speech organs into an optimal starting position to utter the response words instead of keeping them in a neutral position, and this might have speeded the responses. But

\footnotetext{
${ }^{5}$ The length of a syllable was defined as the interval between the onset of its first segment and the onset of the first segment of the next syllable. The means reported for Experiment 1 are based on approximately 180 out of 750 responses from each subject (or $24 \%$ of the responses). Three response words were selected from each set. The length of the first syllable of these words was determined for all valid responses in the last three trials of each block in the second and third parts of the experiment. The means reported for Experiment 6 are based on approximately 144 out of 864 responses per subject (or 17\% of the responses), namely on the valid responses in the last four trials of the second repetition of each block.
}

it seems unlikely that such motor preparation can span more than one syllable. Therefore, the extra effect of the primed second syllable observed in Experiments 5 and 6 must be explained in a different way. Similarly, in other experiments (Meyer, 1988), implicit priming effects were obtained both from word-initial and from word-internal syllable onsets, provided that the preceding syllables were also primed. These findings suggest that, though motor preparation might contribute to the implicit priming effects, they are unlikely to be exclusively caused by it.

Yet another possible explanation of the implicit priming effects is that the primes facilitated the retrieval of the response words. Several studies have shown that the retrieval of words from long-term memory can be aided by phonologically related cues (see, for instance, Freedman \& Landauer, 1963; Gruneberg \& Monks, 1971; Loftus, Senders, \& Turkletaub, 1974). In addition, there are studies in which paired-associate learning tasks were used and in which the subjects' performance was better for word pairs that were systematically related in their forms than for unrelated pairs, presumably because the phonological relationship between the members of the pairs restricted the set of answers considered in each trial (see Bower \& Bolton, 1969; d'Amato \& Diamond, 1979; d'Amato \& Rubenstein, 1981). In the homogeneous test blocks of the present experiments the response words shared one or two syllables, which might have narrowed down the set of possible responses in a similar way. According to this account, the implicit primes were retrieval cues that helped the subjects remember which response words were tested in each block.

However, for methodological reasons such an explanation is less plausible for the present results than for those it was originally proposed for. In Bower and Bolton's (1969), d'Amato and Diamond's (1979), and d'Amato and Rubenstein's (1981) experiments longer test lists (including 18 or 19 
word pairs) were used than in the present experiments. Also, the acquisition of word pairs in a series of trials was investigated, whereas the subjects of the present study were only tested after they said that they knew the word pairs. Perhaps the implicit primes facilitated the acquisition of the word pairs; but by the time the subjects were tested they had most likely created a working memory representation of the three or five relevant word pairs and selected the response words from that list, regardless of whether they were related in form. This assumption is supported by the observation that there were practically no errors in which subjects selected response words that did not belong to the materials of the block being tested. Across all six experiments, which included a total of 47,280 trials, such errors were observed 15 times. Furthermore, under the retrieval cue hypothesis one might expect stronger priming effects at the beginning of the experiments than at the end because the cues should be most helpful when the word pairs had not yet been practiced extensively. However, such interactions of the variables contexts and repetitions were not found in any of the experiments.

Finally, on the retrival cue hypothesis it is difficult to explain why the effects depended on the word positions of the implicit primes. Bower and Bolton (1969), d'Amato and d'Diamond (1979), and d'Amato \& Rubenstein (1981) used monosyllabic words and nonwords and found that rhyming pairs were recalled as well as or better than pairs of words or nonwords that shared the word-onset and the following vowel. By contrast, in the experiments reported above, only primes that included the first syllable of the response words were effective; and in other experiments using monosyllabic response words implicit priming effects were obtained from the onset consonants, but not from the rhymes of the response words (Meyer, 1988).

These findings would be compatible with the retrieval cue account if word-initial and word-final implicit primes differed in how efficiently they narrowed down the sets of possible responses. This could be true if there were substantially fewer Dutch nouns that began in the syllables used as implicit primes in Experiments 1 and 3 than nouns that ended in the syllables used as implicit primes in Experiments 2 and 4. This supposition was tested using the data base of the Center for Lexical Information (CELEX Nijmegen). For each set of Experiments 1 through 4 , the number of disyllabic nouns was determined that had the same stress pattern as the response words and included the primed syllable in the same word position. The word groups defined by the wordinitial syllables used as implicit primes in Experiments 1 and 3 were indeed slightly smaller than the word groups defined by the word-final syllables used as primes in Experiments 2 and 4 . On average the two types of word groups included 19.3 words (standard deviation: $S D=8.6$ ) and 25.3 words $(S D=16.1)$, respectively. But this difference seems too small to explain the presence of strong priming effects in Experiments 1 and 3 and the absence of such effects in Experiments 2 and 4. Moreover, the word groups defined by the implicit primes were also determined for the materials of the experiments using monosyllabic response words that were mentioned above. The word groups defined by the rhyme primes included an average of only 20.4 words $(S D=10.9$ ), while the groups defined by the onset primes included, on an average, as many as 184.2 words $(S D=$ 85.1); yet, priming effects were only found for the latter type of primes.

Of course, other reasons are conceivable for why syllables in different word positions might differ in their efficiency as retrieval cues. For instance, a spreading activation model of lexical access could include the assumption that the link from a word to its first syllable is stronger than the link to the second syllable so that the word is activated more strongly when the first syllable than when the second syllable is 
primed. But on this account it remains unclear why the second syllable of disyllabic response words alone was not an effective prime, whereas an extra priming effect was obtained from the second syllable of trisyllabic response words when the first syllable was also primed.

It should be recalled that the selection of the correct response word for a particular trial from the set of three or five words tested in a given block could not be facilitated by an implict prime because all response words of the block included the prime. In fact, the selection of the response words was probably slightly more difficult in the homogeneous than in the heterogeneous condition. This is suggested by the subjects' tendency to make more errors in the homogeneous than in the heterogeneous conditions. The differences in the error rates were small and only reached significance in Experiment 4 (error rates: $7.2 \%$ vs. $4.85 \%$; Wilcoxon $z=2.09, p<.05$ ) and in Experiment 6 (error rates: $7.85 \%$ vs. $5.6 \% ; z=2.08, p<.05$ ). But a trend toward higher error rates in the homogeneous condition was found in all experiments, including those in which the reaction times were not affected by the primes (see Tables $2,5,8,10,12$, and 14). This effect can probably be allocated on the level of lexical selection. When a given prompt was read, the corresponding response word became highly activated and transmitted some of its activation to its syllables and segments. In the homogeneous condition the response words of a block had one or two syllables in common. Due to feedback from these syllables and their segments, the activation levels of all response words were elevated, which might have rendered the selection of the correct response word more difficult than in the heterogeneous condition, where only the target response word became highly activated when a given prompt was presented.

To summarize, the facilitatory effects of the implicit primes can be regarded as phonological effects. Other accounts are, first, that the subjects uttered the primed parts of the words before selecting the response words; second, that they prepared themselves on the motor level; and third, that they used the primes as cues to remember which words were tested in each block. The data do not suffice to rule out any of these alternative hypotheses with certainty, but none of them offers a fully satisfactory explanation of the data, either. The allocation of the priming effects on the phonological level can be maintained, but more evidence is needed to demonstrate that this interpretation is correct.

Though the interpretation of the priming effects as phonological effects that was outlined above is largely based on Dell's (1986) model of phonological encoding, it presupposes certain modifications and extensions of that model, which eventually must be tested independently. Dell's assumption that the syllable frame is filled at regular time intervals is replaced by the proposal that the frame is filled as soon as one onset, nucleus, and coda segment have reached a certain activation threshold. The model was modified in this way in order to capture the idea that the time necessary to encode a word should depend on how quickly the segments of each of its syllables reach a certain level of activation. The fact that the reactions were speeded by certain types of implicit primes can be regarded as support for this notion. But it remains to be established how well this proposal will fare in other instances, for example, in accounting for the speech error evidence explained by Dell's model.

In addition, certain assumptions were made about the strategies the subjects adopted in the implicit priming experiments. Supposedly, they prepared themselves for the utterance of the response words on the basis of primes that included the first syllable, or the first and second syllable of the response words, but not on the basis of primes that included only the second syllable. The preparation was taken to consist in creating and retaining a pho- 
nological representation of the primes. This process was assumed to be closely related to the normal process of phonologically encoding, taking place whenever a syllable is uttered. It remains to be established if this view of the processes underlying the priming effects is correct. If it is correct, the results of the priming experiments tell us that the syllables of a word must be encoded in a certain order, namely proceeding from the beginning to the end of the word.

\section{APPENDIX}

\section{Response Words of Experiments 1 through 6}

\section{Experiment 1}

Set 1: boete, boeven, boeking, boedel, boezem

Set 2: kabel, kater, kamer, kalief, kano

Set 3: lezing, lepra, lepel, leger, leven

Set 4: poker, poging, poten, pose, polis

Set 5: sinas, citer, silo, sisal, sieraad

\section{Experiment 2}

Set 1: melding, branding, scheiding, voeding, kleding

Set 2: firma, reuma, poema, thema, drama

Set 3: porie, glorie, serie, larie, prairie

Set 4: salto, veto, foto, conto, auto

Set 5: vezel, ijzel, kiezel, reuzel, horzel

\section{Experiment 3}

Set 1: boetiek, boeddhist, boerin, boeket, bouclé

Set 2: decor, depot, decaan, detail, delict

Set 3: komeet, konijn, kozak, koraal, kopie

Set 4: ravijn, raket, rapport, ragout, radijs

Set 5: cipres, citaat, citroen, siroop, sigaar

\section{Experiment 4}

Set 1: briket, kroket, parket, raket, boeket
Set 2: formaat, bromaat, tomaat, klimaat, primaat

Set 3: techniek, paniek, kliniek, tuniek, kroniek

Set 4: proces, exces, abces, reces, succes

Set 5: cultuur, ceintuur, lektuur, montuur, natuur

\section{Experiment 5}

Type 1 sets

Set 1: argument, arsenal, artisjok

Set 2: mirabel, microfoon, mineraal

Set 3: pelikaan, pepermunt, pedagoog

Type 2 sets

Set 4: intellekt, integraal, interesse

Set 5: kolonel, kolonist, koloriet

Set 6: paradijs, parasiet, paraplu

\section{Experiment 6}

Type 1 sets

Set 1: bagatel, bajonet, basiliek

Set 2: diplomaat, didaktiek, dirigent

Set 3: etiket, emigrant, energie

Type 2 sets

Set 4: epiloog, episode, epifyse

Set 5: karamel, karavaan, karabijn

Set 6: monoliet, monogram, monoloog

Note. The complete materials and a translation are available from the author.

\section{REFERENCES}

Baddeley, A. D., Thomson, N., \& Buchanan, M. (1975). Word length and the structure of shortterm memory. Journal of Verbal Learning and Verbal Behavior, 14, 575-589.

BoolJ, G. E. (1981). Generative fonologie van het Nederlands [Generative phonology of Dutch]. Utrecht: Spectrum.

BOOMER, D. S., \& LAVER, J. D. M. (1968). Slips of the tongue. British Journal of Disorders of Communication, 3, 2-12.

Bower, G. H., \& Bolton, L. S. (1969). Why are rhymes easy to learn? Journal of Experimental Psychology, 82, 453-461.

Browman, C. P. (1978). Tip of the tongue and slip of the ear: Implications for language processing (UCLA Working Papers in Phonetics No. 42). University of California, Los Angeles.

Brown, R., \& MCNerll, D. (1966). The 'tipof-the-tongue' phenomenon. Journal of Verbal Learning and Verbal Behavior, 5, 325-337. 
Conrad, R. (1964). Acoustic confusions in immediate memory. British Journal of Psychology, 55, 7584.

D'Amato, M. F., \& Diamond, M. (1979). Role of rules in paired-associate learning. Psychological Reports, 44, 648-650.

D'Amato, M. F., \& Rubenstein, V. (1981). Response-set size and paired-associate learning. Psychological Reports, 48, 172-174.

DELL, G. S. (1986). A spreading activation theory of retrieval in sentence production. Psychological Review, 93, 283-321.

DELL, G. S. (1988). The retrieval of phonological forms in production: Tests of predictions from a connectionist model. Journal of Memory and Language, 27, 124-142.

Dell, G. S., \& RePKA, R. J. Errors in inner speech. In B. Baars (Ed.), The psychology of error: A window on the mind, in press.

Ellis, A. W. (1980). Errors in speech and short-term memory: The effects of phonemic similarity and syllable position. Journal of Verbal Learning and Verbal Behavior, 19, 624-634.

FAY, D., \& CutLER, A. (1977). Malapropisms and the structure of the mental lexicon. Linguistic Inquiry, 8, 505-520.

Freedman, J. L., \& Landauer, T. K. (1966). Retrieval of long-term memory: "Tip-of-the-tongue" phenomenon. Psychonomic Science, 4, 309-310.

Fromkin, V. A. (1971). The non-anomalous nature of anomalous utterances. Language, 47, 27-52.

Fromkin, V. A. (1973). Introduction. In V. A. Fromkin (Ed.), Speech errors as linguistic evidence (pp. 11-45). The Hague: Mouton.

FudGE, E. C. (1969). Syllables. Journal of Linguistics, 5, 253-286.

GARRETT, M. F. (1975). The analysis of sentence production. Advances in research and theory. In G. H. Bower (Ed.), The psychology of learning and motivation (Vol. 9, pp. 133-177). New York: Academic Press.

GARRETT, M. F. (1980). Levels of processing in sentence production. In B. Butterworth (Ed.), Language production. Vol 1. Speech and talk (pp. 177-220). New York: Academic Press.

GoLDSMITH, J. (1976). An overview of autosegmental phonology. Linguistic Analysis, 2, 23-68.

GruneberG, M. M., \& Monks, J. (1971). “Feeling of knowing" and cued recall. Acta Psychologica, 38, 257-265.

Halle, M., \& Vergnaud, J.-R. (1980). Three dimensional phonology. Journal of Linguistic Research, 1, 83-105.

VAN DER HULST, H. (1984). Syllable structure and stress in Dutch. Dordrecht: Foris.

KAHN, D. (1976). Syllable-based generalizations in English phonology, doctoral dissertation. Massachusetts Institute of Technology, Cambridge.
KeMPEN, G., \& HoEnKamp, E. (1987). An incremental procedural grammar for sentence formulation. Cognitive Science, 11, 201-258.

KrAayeveld, J. (1988). Delayed-onset studies: The influence of word length on word production latencies, unpublished master's thesis. Leiden University.

LEVELT, W. J. M. (1989). Speaking: From intention to articulation. Cambridge, MA: MIT Press.

Liberman, M., \& Prince, A. (1977). On stress and linguistic rhythm. Linguistic Inquiry, 8, 249-336.

Loftus, E. F., Senders, J. W., \& Turkletaub, S. (1974). The retrieval of phonetically similar and dissimilar category members. American Journal of Psychology, 87, 57-63.

MacKay, D. G. (1970). Spoonerisms: The structure of errors in the serial order of speech. Neuropsychologia, 8, 323-350.

MACKAY, D. G. (1972). The structure of words and syllables: Evidence from errors in speech. Cognitive Psychology, 3, 210-227.

MACKAY, D. G. (1982). The problems of flexibility, fluency, and speed-accuracy trade-off in skilled behavior. Psychological Review, 89, 483-506.

MACKAY, D. G. (1987). The organization of perceptions and action. $A$ theory for language and other cognitive skills. New York: Springer Pub.

MeYer, A. S. (1988). Phonological encoding in language production: $A$ priming study, unpublished doctoral dissertation, University of Nijmegen.

Nooteвoom, S. G. (1969). The tongue slips into patterns. In A. G. Sciarone, A. J. van Essen, \& A. A. van Raad (Eds.), Nomen: Leyden studies in linguistics and phonetics (pp. 114-132). The Hague: Mouton.

Selkirk, E. O. (1982). The syllable. In H. van der Hulst \& N. Smith (Eds.), The structure of phonological representations (Part II, pp. 337-383). Dordrecht: Foris.

SELKIRK, E. (1984). On the major class features and syllable theory. In M. Aronoff \& R. T. Oehrle (Eds.), Language sound structure. Cambridge, MA: MIT Press.

ShatTUCK-HufNagel, S. (1979). Speech errors as evidence for a serial-ordering mechanism in sentence production. In W. E. Cooper \& E. C. T. Walker (Eds.), Sentence processing: Psycholinguistic studies presented to Merrill Garrett (pp. 295-342). Hillsdale, NJ: Erlbaum.

ShatTuck-Hufnagel, S. (1983). Sublexical units and suprasegmental structure in speech production planning. In P. F. MacNeilage (Ed.), The production of speech (pp. 109-136). New York: Springer Pub.

ShatTuck-Hufnagel, S. (1987). The role of wordonset consonants in speech production planning: New evidence from speech error patterns. In E. Keller \& M. Gopnik (Eds.), Motor and sensory 
processes of language (pp. 17-51). Hillsdale, NJ: Erlbaum.

Stemberger, J. P. (1983). The nature of $/ \mathrm{r} /$ and $/ 1 /$ in English: Evidence from speech errors. Journal of Phonetics, 11, 139-147.

Stemberger, J. P. (1984). Wordshape errors in language production (Research on Speech Perception Progress Rep. No. 10, pp. 265-300). Bloomington, IN: Indiana Univ. Speech Research Laboratory.

Stemberger, J. P. (1985). An interactive activation model of language production. In A. W. Ellis (Ed.), Progress in the psychology of language (Vol. 1, pp. 143-186). London: Erlbaum.
Treiman, R. (1983). The structure of spoken syllables: Evidence from novel word games. Cognition, 15, 49-74.

Treiman, R. (1984). On the status of final consonant clusters in English syllables. Journal of Verbal Learning and Verbal Behavior, 23, 343-356.

Treiman, R. (1986). The division between onsets and rimes in English syllables. Journal of Memory and Language, 25, 476-491.

Treiman, R., \& DANis, C. (1988). Syllabification of intervocalic consonants. Journal of Memory and Language, 27, 87-104.

(Received June 7, 1989)

(Revision received December 28, 1989) 